\title{
Adsorption of Lead from Aqueous Solution onto Untreated Orange Barks: Equilibrium, Kinetics and Thermodynamics
}

\author{
N. Azouaou', Z. Sadaoui ' and H.Mokaddem ${ }^{\prime}$ \\ University of Sciences and Technology Houari-Boumediene, USTHB, Laboratory of Reaction Genius, Faculty of Mechanical \\ and Processes Genius, , BP n³2 El Alia bab ezzouar 16111 Algiers, Algeria.
}

\begin{abstract}
Adsorption can be used as a cost effective and efficient technique for the removal of toxic heavy metals from wastewater. Waste materials with no further treatment such as orange barks from commercial oranges may act as adsorbent for the removal of lead. Batch kinetic and equilibrium experiments were conducted to study the effects of contact time, adsorbent dose, initial $\mathrm{pH}$, particle size, initial concentration of lead and temperature. Three adsorption isotherm models namely, Langmuir, Freundlich and Dubinin-Radushkevich were used to analyse the equilibrium data. The Langmuir isotherm which provided the best correlation for $\mathrm{Pb}^{2+}$ adsorption onto orange barks shows that the adsorption was favourable and the maximum adsorption capacity found was equal to $\mathbf{1 1 2 . 3 5 9} \mathbf{m g . g}$. Thermodynamic parameters were evaluated and the adsorption was exothermic. The equilibrium was achieved less than $30 \mathrm{~min}$. The adsorption kinetic data was fitted with first and second order kinetic models. Finally it was concluded that the lead adsorption kinetic onto orange barks was well fitted by second order kinetic model rather than first order model. The results suggest that orange barks have high possibility to be used as effective and economical adsorbent for $\mathrm{Pb}^{2+}$ removal.
\end{abstract}

Keywords: Lead, Adsorption, Kinetic study, Thermodynamic study, Equilibrium isotherm. 